\title{
Tensile strength of a vegetated and partially saturated soil
}

\author{
Alessandro Fraccica ${ }^{1,2^{*}}$, Enrique Romero ${ }^{1}$, Thierry Fourcaud $^{2}$, Mercedes Sondon $^{1}$, and Luis Gandarillas ${ }^{3}$ \\ ${ }^{1}$ Universitat Politècnica de Catalunya, CIMNE, Barcelona, Spain \\ ${ }^{2}$ AMAP, CIRAD, CNRS, INRA, IRD, Univ. Montpellier, Montpellier, France \\ ${ }^{3}$ GIC S.r.l., Cochabamba, Bolivia
}

\begin{abstract}
Vegetated soil's shear strength has been usually assessed through direct shear tests and under triaxial compression stress paths while less is known about its behaviour under tensile stress. Tensile strength and shrinkage-induced cracking play a crucial role in the hydro-mechanical response of earth structures exposed to drying/wetting cycles. For this purpose, a new device for direct tensile tests has been designed and used to let plants grow in compacted soil samples. The equipment consists of two cylindrical moulds connected to each other by a soil bridge in which failure upon pulling is induced due to geometrical constraints. Different soil's mechanical responses were observed depending on whether suction was low or high. Indeed, it was detected an increase of soil tensile strength and a more brittle behaviour as suction was increasing. However, at the same suction, vegetated soil's response was more ductile than that of the corresponding bare soil. Results were analysed within a shear strength criterion for partially saturated soils. The analysis evidenced an increase in shear strength in the vegetated soil. A correlation was found between this increase and the roots' mechanical and morphological features.
\end{abstract}

\section{Introduction and background}

Global warming has led to more extended periods of drought and isolated heavy rainfalls. These events are particularly detrimental in fine-grained soils: very intense drying and wetting cycles generate cracks and alter their hydro-mechanical and structural properties $[1,2]$. This cracking affects the behaviour of slopes and embankments made with these soils, causing a faster response to rainfall infiltration, affecting their behaviour at the serviceability state and inducing phenomena of shallow or deep instability [3,4]. In the framework of sustainable engineering, it is essential to understand which is the role of vegetation in affecting the hydromechanical behaviour of geotechnical structures [5]. Plant roots were found to enhance soil shear strength $[6,7]$, but less is known about their effects on soil tensile behaviour and shrinkage-induced cracking. This lack of knowledge may lead to an incorrect prediction of the sliding surface of a landslide, as proved by recent research [8].

Investigations coming from agronomy have produced many results on plants pull-out [9-12] and roots' tensile strength $[7,13]$. Anyway, from this kind of results, it is difficult to infer how soil's mechanical properties were modified by roots.

In the geotechnical framework, examples of bare soil tensile strength have been provided in the literature $[14,15]$. The research by [14] observed a peak and a subsequent decrease in soil tensile strength as the degree of saturation was decreasing. Nevertheless, [16] detected an increase in clay tensile strength on drying starting from compacted and remoulded states. The studies by $[17,18]$ on soil reinforced by natural fibres manually distributed within the matrix reported a delay in crack initiation, a reduction in crack propagation properties, and an increase in soil tensile strength as fibres' content was increasing.

To the authors' best knowledge, there is no literature on tensile tests on soils with vegetation. In this regard, an apparatus was designed and built to allow plant growth in compacted soil and to test the reinforced material under tensile stress. This work aims at comparing the first results obtained on fallow and vegetated samples at different initial matric suctions. Results were analysed using a shear strength failure criterion with microstructural features provided by [19] for partially saturated soils.

\section{Equipment for direct tensile strength tests}

The equipment consists of two 3D printed cylindrical moulds made of ABS polymer (density: $1.05 \mathrm{Mg} / \mathrm{m}^{3}$, tensile strength (printed): $27.59 \mathrm{MPa}$, elastic modulus (printed): $1.20 \mathrm{GPa}$ [20], water absorption after $24 \mathrm{~h}$ of saturation: $0.2-0.4 \%$ [21]). The moulds are kept together by a bridge made of two removable ABS L-shaped pieces, and their sizes are indicated in Figure 1. The internal base of the moulds presents grooves to increase the adherence at the interface with the soil. The moulds are mounted on rails, the dynamic friction of which is

*Corresponding author: alessandrofraccica@gmail.com 
minimised by linear ball bearings (calibrated dynamic friction coefficient equal to 0.002 ).

At the end of each mould, metal plates are used to connect to a load cell (RSC-1 type, Remberg, Spain, FS $=500 \mathrm{~N}$, precision $0.2 \mathrm{~N}$ ) and on the other end to a motor for displacement control (Starvert-i, Omadisa, Spain). An LVDT (D5-200AG, RDP Electronics, UK, $\mathrm{FS}=10 \mathrm{~mm}$, linearity error $0.5 \% \mathrm{FS}$ ) has also been installed to record the horizontal displacement redundantly.

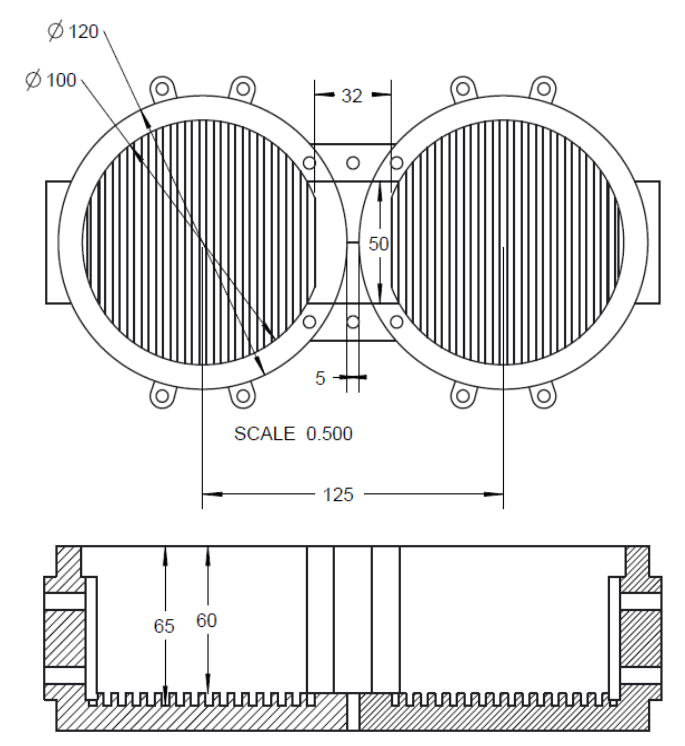

Fig. 1. Horizontal and vertical cross-sections of the new tensile strength equipment (sizes in $\mathrm{mm}$ ).

\section{Material and experimental protocols}

\subsection{Material}

Laboratory tests were performed on silty sand retrieved at the Llobregat river's delta in Barcelona. Its granulometric composition is: $5.4 \%$ of clay, $25.4 \%$ of silt, $28 \%$ of sand, $41.2 \%$ of gravel [22], its plasticity index ranges between 9.6 and $13.5 \%$ and its density of solid particles is $2.65 \mathrm{Mg} / \mathrm{m}^{3}$ [5,22]. For this study, the soil has been sieved through ASTM \#4 (4.76 mm).

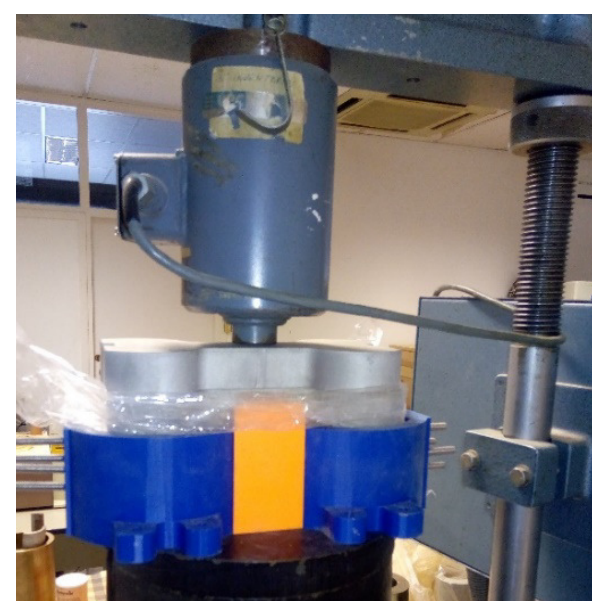

Fig. 2. Static compaction of the soil inside the moulds.

\subsection{Compaction and plant growth}

The soil was statically compacted in two layers in the moulds using a metal plate specifically built with the same shape of the equipment (Fig. 2). Water content at compaction was $w=15 \%$, matric suction $s=40 \mathrm{kPa}$ and dry density $\rho_{d}=1.60 \mathrm{Mg} / \mathrm{m}^{3}$. Resulting void ratio was $e=0.67$ and degree of saturation $S_{r}=0.61$. Maximum total vertical stress applied on compaction was $100 \mathrm{kPa}$. The final height of the samples was $40 \mathrm{~mm}$. After compaction, 6 samples were seeded with Cynodon dactilon, adopting a seeding density of $34 \mathrm{~g} / \mathrm{m}^{2}$ and placing the seeds in $2 \mathrm{~mm}$ deep and $40 \mathrm{~mm}$ spaced holes (Fig. 3). After seeding, samples were kept at a water content $w=21 \%$ and matric suction $s=1 \mathrm{kPa}$ using an automatic irrigation system (Fig. 3), while suction was monitored by a ceramic-tip tensiometer (T5x, UMS, Germany). This condition was kept constant throughout the growing period of the plants (3 months). For comparison purposes, 7 fallow specimens were subjected to the same hydraulic history.

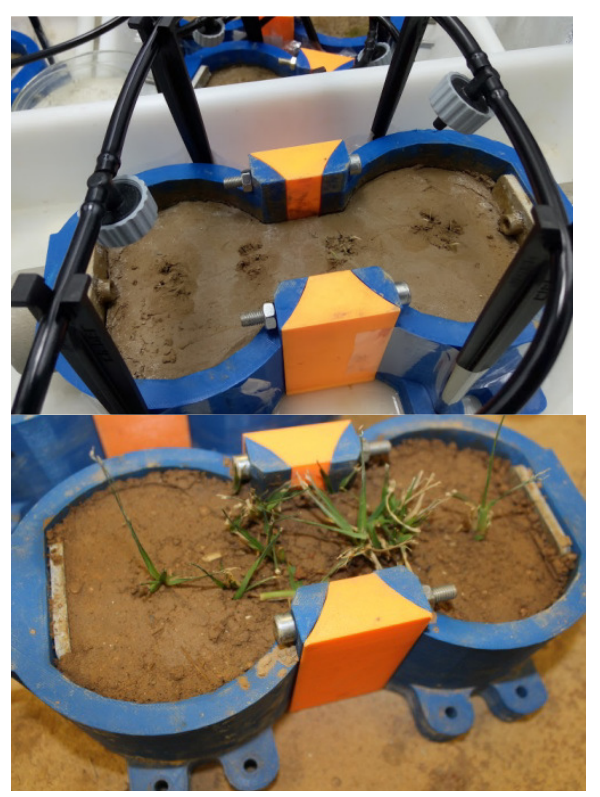

Fig. 3. Samples before and after roots growth.

\subsection{Tensile strength tests}

After plants growth, samples were dried to the desired suction -checked by tensiometer- in a temperature/relative humidity-controlled room $\left(T=20^{\circ} \mathrm{C}\right.$, $h_{r}=50 \%$ ). Samples were wrapped in film and left in darkness for 3 hours, allowing suction equalisation. Then, tensile tests started at a displacement rate of 0.080 $\mathrm{mm} / \mathrm{min}$ until cracking was reached in the samples. Vegetated soils were tested beyond soil crack occurrence to follow their post-peak behaviour. Indeed, some roots were still in tension and crossing the discontinuity generated by the tests. The further displacement imposed by the device was aimed at testing roots until their complete pull-out or fine-root breakage. These phenomena have not always been achieved, due to displacement limitations of the equipment (maximum displacement allowed: $d_{\max }=22 \mathrm{~mm}$ ). 


\subsection{Suction and water content measurements}

Matric suction was measured along each tensile test using a ceramic-tip tensiometer. The tensiometer tip was installed at a depth of $20 \mathrm{~mm}$ in the soil and $70 \mathrm{~mm}$ away from the central section of the equipment to avoid affecting soil's mechanical response. The average variation of suction along each test was $\Delta s=(5 \pm 2) \mathrm{kPa}$. The value of matric suction corresponding to each test was selected as the one measured when the maximum tensile stress was reached.

Water content was measured before each tensile test by oven-drying according to [23] on small soil samples retrieved on the soil surface. After each tensile test, two samples were also extracted for oven-drying: one in correspondence of the tensiometer's installation point, and one in correspondence of the crack generated by the test. Visual inspection has allowed excluding roots from the oven-drying specimens. The average difference between the initial and the final measurements was $\Delta w=$ $(0.10 \pm 0.03) \%$. For this reason, the value of water content corresponding to each test was determined as the average of the different measurements.

\subsection{Void ratio evaluation}

After each tensile test, a cube of soil close to the crack was extracted by a spatula, to evaluate its bulk density by paraffin test [24] and determine its void ratio.

Vegetated samples were broken after paraffin tests to recover the roots included. The roots were weighed and their volume $V_{\text {roots }}$ evaluated by pycnometry, as explained in [25]. From the mass of roots and knowing the soil water content it was possible to evaluate the mass of the solid particles included in the samples. From this value, the volume of solid particles $V_{s}$ was inferred. Then, the volume of voids $V_{v}$ was calculated as:

$$
V_{v}=V_{\text {tot }}-V_{\text {roots }}-V_{s}
$$

where $V_{t o t}$ is the sample's volume (including the volume of roots) given by the paraffin test. After these measurements, the void ratio $e=V_{v} / V_{s}$ was evaluated that allowed calculating the degree of saturation $S_{r}$ corresponding to each test.

\subsection{Roots morphological characterisation}

After each test on vegetated samples, the diameters of all the roots present in the generated crack were measured by means of a calliper (precision $0.020 \mathrm{~mm}$ ). Then, the Root Area Ratio $R A R$ was calculated as

$$
R A R=\Sigma_{i} A_{r, i} / A_{s}
$$

where $A_{r, i}$ is the area of a given root $i$ and $A_{s}$ is the vertical section area of soil. Since cracks were always observed in the connecting bridge between moulds, $A_{s}$ was always equal to $50 \times 40 \mathrm{~mm}^{2}$. This index has been used in literature to quantify roots presence and reinforcement of the soil $[6,13,26,27]$.

\section{Experimental results}

\subsection{Soil tensile behaviour}

Tensile tests were carried out at different matric suctions. In Fig. 4, comparisons of the evolution of tensile (total) stress between bare and vegetated soils are presented for low and high matric suctions. For each vegetated test, the corresponding $R A R$ is indicated in the legend. The vegetated soil presents a higher soil tensile strength than the fallow soil. Samples at low suction (Fig. 4. a) exhibit ductile behaviour, which is enhanced by roots. Moreover, the peak in tensile stress in the vegetated sample at very low suction is observed to be delayed with respect to the fallow soil at slightly higher suction. Samples at high suction (100 kPa, Fig. 4.b) present a more brittle behaviour, with a sudden strength loss after the peak (particularly in the bare soil sample). Anyway, roots are providing a strength increase and a slight attenuation of the soil's brittleness.
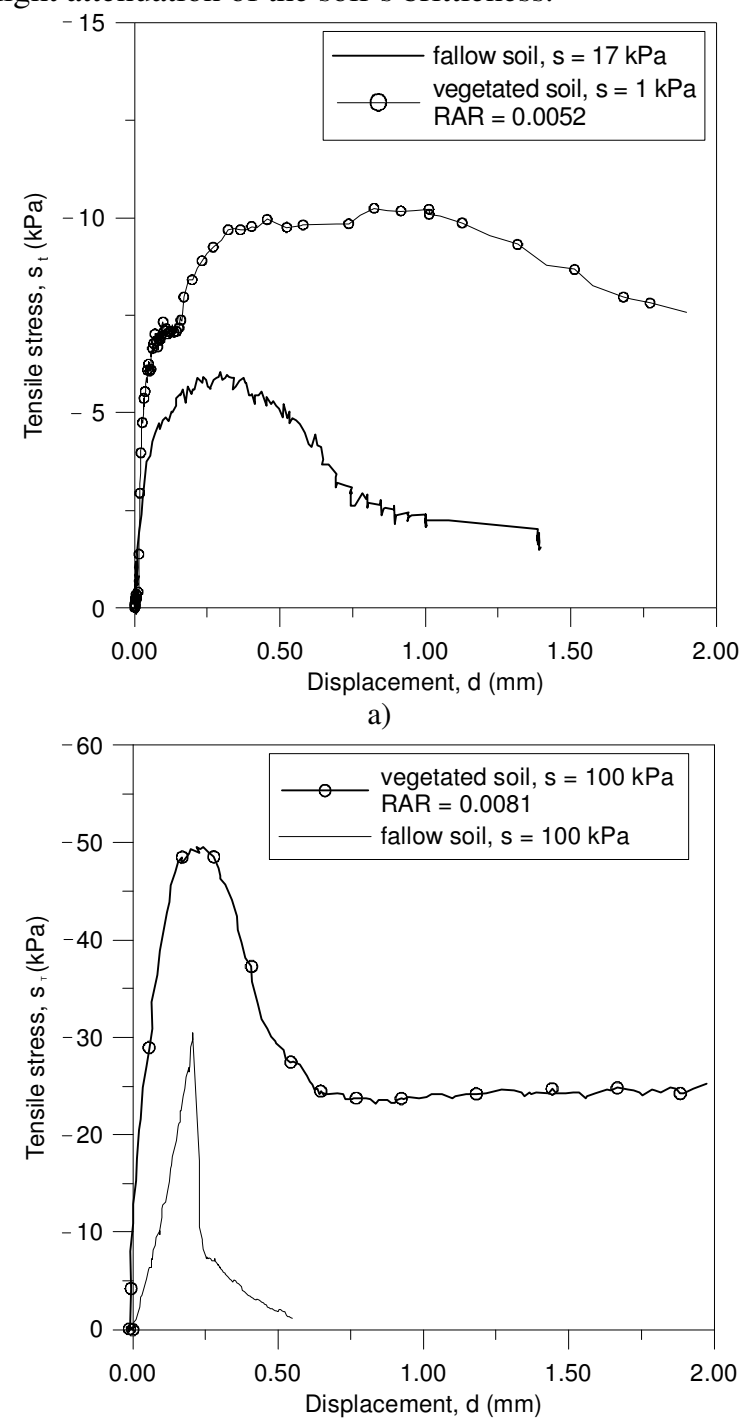

b)

Fig. 4. Tensile stress-displacement curves of fallow and vegetated samples. a) At $s=1 \mathrm{kPa}\left(S_{r}=0.81\right)$ in vegetated and $17 \mathrm{kPa}\left(S_{r}=0.86\right)$ in fallow soil. b) $s=100 \mathrm{kPa}\left(S_{r}=0.70\right)$ in vegetated and $s=100 \mathrm{kPa}\left(S_{r}=0.83\right)$ in fallow soil 
The different stress-displacement behavioural features observed between low and high suctions is explained by the contrasting mechanisms of failure of roots, as observed by [9]. In wet soils, roots are more likely to be pulled-out whereas, in dry soils, roots are more likely to break. In the former case, a higher displacement is needed to reach root failure, but root tensile resistance may not be fully exploited. When suction increases, the soil shrinks firmly holding dry roots and therefore promoting their breakage. Stressdisplacement curves for other tests carried out at different suctions are presented in [25]. Fallow soil tests were carried out at matric suctions between 1 and 300 $\mathrm{kPa}$ while vegetated soil tests between 1 and $190 \mathrm{kPa}$.

\subsection{Soil hydraulic response}

Values of matric suction as a function of the degree of saturation, measured during each vegetated and fallow tensile test, are compared in Fig. 5. At the same degree of saturation, vegetated soil exhibited less matric suction than bare soil. This is directly induced by the higher void ratio observed with paraffin tests in the vegetated samples, with respect to fallow samples at the same suction. The response is in line with other observations and is caused by dramatic changes in soil structure due to roots growth (generation of fissures) [22,28].

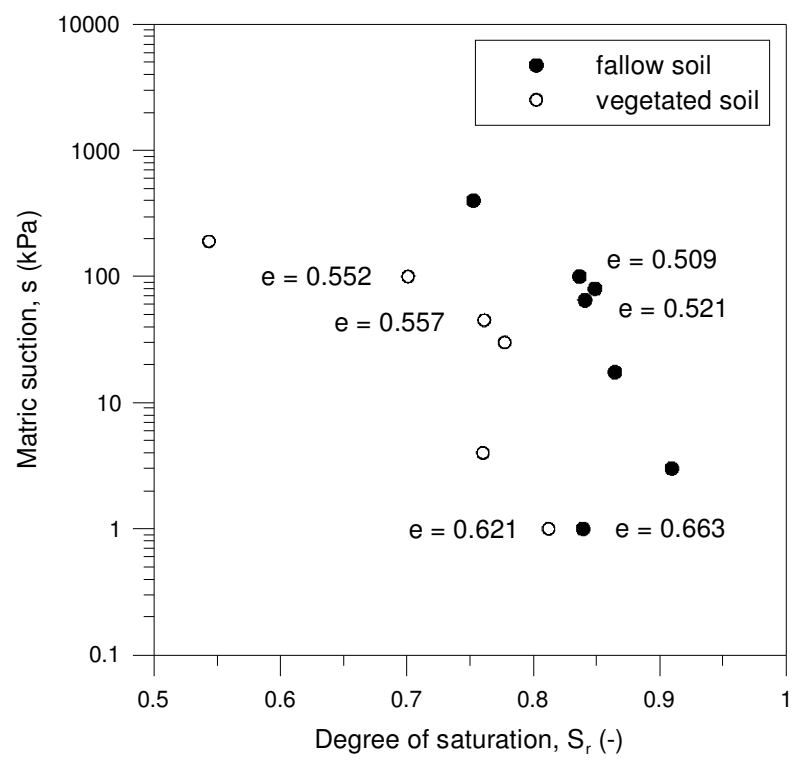

Fig. 5. Degrees of saturation and matric suctions at which vegetated and fallow tensile tests were carried out. Void ratios are indicated close to the respective $S_{r}-s$ points.

\section{Hydro-mechanical framework}

Results were analysed with the constitutive stress framework (mean average skeleton stress $p^{\prime}$ ) for partially saturated soils proposed by $[19,29]$ :

$$
p^{\prime}=\left(p-u_{a}\right)+S_{r}^{\alpha} s
$$

where $p$ is the total mean stress, $u_{a}$ the air pressure, $s$ the matric suction, $S_{r}$ the degree of saturation and $\alpha$ a model parameter that depends on the soil type and microstructure.

Tensile (total) stress was considered as the minimum total principal stress $\sigma_{3}$ while total stresses in the other two principal directions are $\sigma_{1}=\sigma_{2}=0 \mathrm{kPa}$ throughout the duration of each test. It was assumed that tensile strength was ruled by failure in shear according to the Mohr-Coulomb failure criterion. Deviator stress is defined as $q=\sigma_{1}-\sigma_{3}=-\sigma_{3}$. The failure criterion under axisymmetric extension is given by:

$$
q_{f}=6 c^{\prime} \cos \varphi^{\prime} /\left(3+\sin \varphi^{\prime}\right)+M_{e} p^{\prime}
$$

with $M_{e}=6 \sin \varphi^{\prime} /\left(3+\sin \varphi^{\prime}\right)$, where $\varphi^{\prime}$ is the friction angle, and $c$ ' the cohesion under saturated state. The mean effective stress $p^{\prime}$ is extended to unsaturated states according to Equation (3).

Deviator and mean average skeleton stresses at failure were calculated considering $\sigma_{3}$ equal to the peak tensile (total) stress of the tensile stress - displacement curves. Tensile strength results from seven fallow soil tests and six vegetated soil tests were used to calibrate by least squares fitting two sets of parameters $M_{e}, c^{\prime}$ and $\alpha$. The calibrated parameters of the failure criterion are presented in Table 1. As observed, the vegetated soil displayed cohesion at saturation and a slightly higher friction angle.

Table 1. Calibrated parameters for the average skeleton stress framework using Mohr-Coulomb failure criterion.

\begin{tabular}{|c|c|c|}
\hline & Fallow soil & Vegetated soil \\
\hline$M_{e}(-)$ & 0.94 & 0.98 \\
\hline$\alpha(-)$ & 4.92 & 2.14 \\
\hline$\varphi^{\prime}\left(^{\circ}\right)$ & 34 & 36 \\
\hline$c^{\prime}(k P a)$ & 0 & 6.3 \\
\hline
\end{tabular}

The two failure envelopes, together with the points at failure $\left(p_{f}, q_{f}\right)$ corresponding to each test, are plotted in Fig. 6. For both materials, the model predicts well the results obtained (coefficients of determination: $R_{\text {fallow }}^{2}=$ $\left.0.99, R_{\text {vegetated }}^{2}=0.94\right)$. Moreover, the vegetated soil presents a higher shear strength than the bare soil even at null mean average skeleton stress, which confirms the contribution of plants to increase soil shear strength $[6,7]$.

The calibrated shear strength parameters were in good agreement, in terms of $\varphi$ ' and $c^{\prime}$, to those calibrated with triaxial tests by [25] on the same fallow and vegetated soil and displaying a similar normalised quantity of roots $\left(\varphi_{\text {fallow }}^{\prime}=35.1^{\circ}, c_{\text {fallow }}^{\prime}=0 \mathrm{kPa}, \varphi^{\prime}{ }_{\text {vegetated }}=\right.$ $\left.36.6^{\circ}, c^{\prime}{ }_{\text {vegetated }}=10 \mathrm{kPa}\right)$. In spite of the detrimental effect of roots on soil hydraulic behaviour (decrease of the retention capacity, as evidenced in Fig. 5), soil mechanical properties were enhanced, within the range of suction investigated.

The calibration of a lower $\alpha$ parameter in the vegetated soil is linked to the modifications induced by roots growth on soil microstructure. Indeed, the effective degree of saturation $S_{r}^{\alpha}$ is associated with the quantity of water in macropores [19]. So, for the same $S_{r}$, if $\alpha$ decreases, the effective degree of saturation increases, meaning that there is a higher volume of water in the 
macropores. This fact is consistent with the rise of this class of pores in a vegetated soil, which was observed by $[22,30]$. Moreover, the calibrated $\alpha$ values are comparable to those calibrated for similar soils in the literature [19].

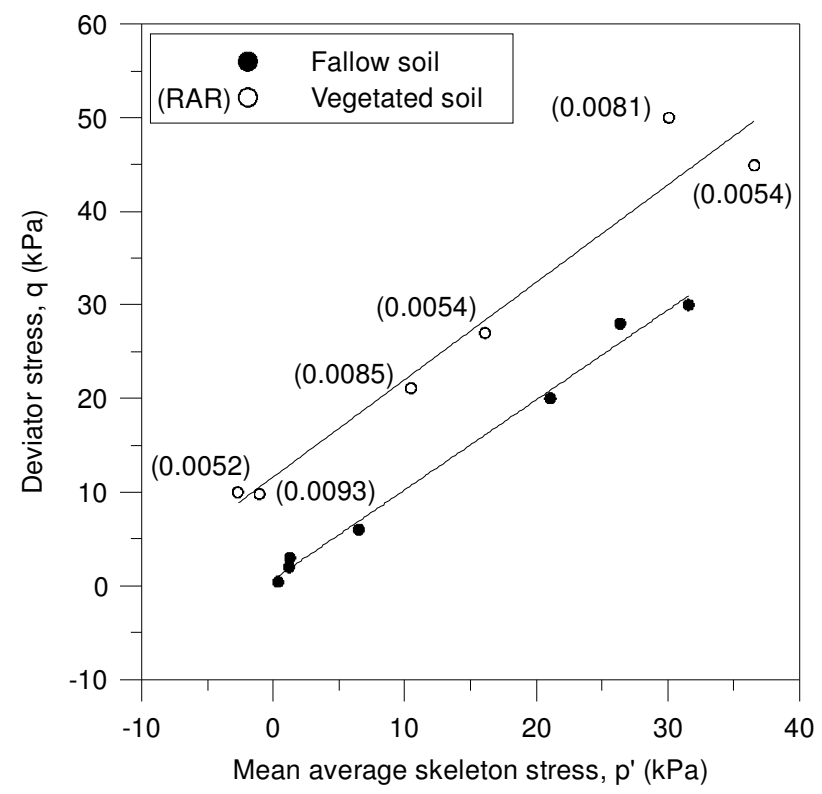

Fig. 6 Failure envelopes and stresses at failure for tensile tests on vegetated and fallow samples.

Close to each point for vegetated soil plotted in Fig. 6, the corresponding $R A R$ is indicated as labels. Its average value is equal to $0.007 \pm 0.0015$. Further roots morphological features measured during these tests are provided in [25]. To consider the effect of this morphological plant trait on soil behaviour, the factor $\beta \cdot \sigma_{t, \text { roots }} \cdot R A R$ was correlated $\left(R^{2}=0.95\right)$ to the increase in soil shear strength $\Delta q=q_{\text {veg }}-q_{\text {fallow. In the }}$ formulation, $q_{v e g}$ is given by each of the vegetated soils' points in the $\left(p^{\prime}, q\right)$ plane, while $q_{\text {fallow }}$ was evaluated at the same mean average skeleton stress. The tensile strength of the roots considered was $\sigma_{t, \text { roots }}=3.5 \mathrm{MPa}$ [25]. The calibrated $\beta$ is equal to 0.41 . This result is in line with observations by other authors [6,7,25]. It demonstrates the usefulness of using these plants' indicators in predicting the contribution of roots to soil shear strength and tensile strength increase. Moreover, the correlation was found to work well even in extension paths, while so far, it was tested only under triaxial compression stress paths $[6,7,25]$.

\section{Concluding remarks}

This paper presented results using a new apparatus that allowed testing a compacted partially saturated sandy soil under direct uniaxial tensile stress, with the facility of growing plants inside it. All the samples were compacted at the same hydraulic state, then wetted under unconfined conditions to let the plants grow and finally dried to the desired matric suctions.
Roots affected soil mechanical response at low and high values of suction, inducing the soil to sustain higher tensile stresses and to withstand higher tensile displacements before cracking, with respect to the fallow soil at similar hydraulic states. Moreover, different roots' failure mechanisms (pulled-out and breakage of roots) were inferred by comparing vegetated soil responses at low and high matric suctions.

Soil matric suction was monitored throughout the tensile tests and the degree of saturation evaluated with a specific procedure at the end of each test. Tensile strength results were interpreted with a Mohr-Coulomb shear strength criterion for partially saturated soils in terms of average skeleton stress. Shear strength parameters obtained were consistent with those evaluated by other geotechnical tests carried out on the same soil and plants, but following different stress-paths (axial compression triaxial tests). This outcome showed that tensile tests could be successfully interpreted and predicted by a soil shear strength criterion.

Roots geometrical features assessed in the tested samples were directly correlated, jointly with a root mechanical feature, to soil shear strength increase (and consequently to tensile strength increase). A formulation provided in literature for soil reinforcement subjected to triaxial compression stress paths was validated under tensile stresses.

The results obtained provided the basis for further evaluation of soil-root interface phenomena at different hydraulic states, and confirm the good performance of plants in preventing soil cracking. Additional laboratory tests will be carried out to improve the correlation through the use of other roots' morphological indexes (Root length density, branching distance, diameter) and plant species.

\section{Acknowledgments}

The authors wish to acknowledge the support of the European Commission via the Marie Skłodowska-Curie Innovative Training Networks (ITN-ETN) project TERRE 'Training Engineers and Researchers to Rethink geotechnical Engineering for a low carbon future' (H2020-MSCA-ITN2015-675762).

Alessandro Fraccica also wishes to acknowledge the fruitful discussions with the members of TERRE and SMUCPHY Projects and with Prof. Alberto Ledesma.

\section{References}

1. B. Albrecht and C. H. Benson, J. Geotech. Geoenvironmental Eng. 127, 67 (2001).

2. J. A. Cordero, G. Useche, P. C. Prat, A. Ledesma, and J. C. Santamarina, 272 (2017).

3. P. J. Vardon, J. Environ. Geotech. 2, 166 (2014).

4. M. Sánchez, D. Wang, J. L. Briaud, and C. Douglas, Transp. Geotech. 1, 257 (2014).

5. R. Oorthuis, M. Hürlimann, A. Fraccica, A. Lloret, J. Moya, C. Puig-Polo, and J. Vaunat, Water (Switzerland) 10, 688 (2018).

6. T. H. Wu, W. P. McKinnell III, and D. N. Swanston, 
Can. Geotech. J. 16, 19 (1979).

7. S. Mickovski, P. D. Hallett, M. F. Bransby, M. C. R. Davies, R. Sonnenberg, and A. G. Bengough, Soil Sci. Soc. Am. J. 73, 1276 (2009).

8. G. Chen, S. Zheng, J. Zhu, W. Wang, and W. Feng, Landslides 17, 471 (2020).

9. N. Pollen, Catena 69, 197 (2007).

10. O. Hamza, A. G. Bengough, M. F. Bransby, M. C. R. Davies, and P. D. Hallett, in Eco- Gr. BioEngineering Use Veg. to Improv. Slope Stab., edited by A. Stokes and et al. (Springer, 2007), pp. 213221.

11. Y. Li, Y. Wang, Y. Wang, and C. Ma, Catena 158, 148 (2017).

12. X. Ji, X. Cong, X. Dai, A. Zhang, and L. Chen, J. Mt. Sci. 15, 882 (2018).

13. S. De Baets, J. Poesen, B. Reubens, K. Wemans, J. De Baerdemaeker, and B. Muys, Plant Soil 305, 207 (2008).

14. M. R. Lakshmikantha, P. C. Prat, and A. Ledesma, 284, 264 (2012).

15. I. Murray and A. Tarantino, Geotechnique 69, 701 (2019).

16. H. Trabelsi, E. Romero, and M. Jamei, Appl. Clay Sci. 162, 57 (2018).

17. P. V Divya, B. V. S. Viswanadham, and J. P. Gourc, J. Mater. Civ. Eng. 26, 14 (2014).

18. H. Trabelsi, M. Chebbi, H. Guiras, M. Jamei, and E. Romero, in 7th Int. Conf. Unsaturated Soils, UNSAT2018 (Hong Kong: The Hong Kong University of Science and Technology (HKUST), 2018), pp. 545-550.

19. E. E. Alonso, J. M. Pereira, J. Vaunat, and S. Olivella, Géotechnique 60, 913 (2010).

20. Z. Weng, J. Wang, T. Senthil, and L. Wu, Mater. Des. 102, 276 (2016).

21. Interstate Plastics Inc., (2019).

22. A. Fraccica, E. Romero, and T. Fourcaud, in $I S$ Glasgow, edited by A. Tarantino and E. Ibraim (EDP Sciences, Glasgow, 2019), p. 12014.

23. ASTM D2216, (2019).

24. ASTM D7263, (2018).

25. A. Fraccica, Experimental Study and Numerical Modelling of Soil-Roots Hydro-Mechanical Interactions, Universitat Politècnica de Catalunya; Université de Montpellier, PhD Thesis, 2019.

26. F. Danjon, D. H. Barker, M. Drexhage, and A. Stokes, Ann. Bot. 101, 1281 (2008).

27. T. Liang, J. A. Knappett, A. G. Bengough, and Y. X. Ke, Landslides 1 (2017).

28. C. W. W. Ng, A. K. Leung, and K. X. Woon, Can. Geotech. J. 51, 311 (2014).

29. S. K. Vanapalli, D. G. Fredlund, D. E. Pufahl, and A. W. Clifton, Can. Geotech. J. 33, 379 (1996).

30. A. Carminati, D. Vetterlein, N. Koebernick, S.
Blaser, U. Weller, and H. J. Vogel, Plant Soil 367, 651 (2013). 